\title{
Number of Sentinel Medical Institutions Needed for Estimating Prefectural Incidence in Influenza Surveillance in Japan
}

\author{
Shuji Hashimoto ${ }^{1}$, Miyuki Kawado ${ }^{1}$, Yoshitaka Murakami ${ }^{2}$, Akiko Ohta ${ }^{3}$, Mika Shigematsu ${ }^{4}$ \\ Yuki Tada ${ }^{4}$, Kiyosu Taniguchi ${ }^{5}$, and Masaki Nagai ${ }^{3}$ \\ ${ }^{1}$ Department of Hygiene, Fujita Health University School of Medicine, Toyoake, Aichi, Japan \\ ${ }^{2}$ Department of Medical Statistics, Shiga University of Medical Science, Otsu, Japan \\ ${ }^{3}$ Department of Public Health, Saitama Medical University Faculty of Medicine, Moroyama, Saitama, Japan \\ ${ }^{4}$ Infectious Disease Surveillance Center, National Institute of Infectious Diseases, Tokyo, Japan \\ ${ }^{5}$ Department of Clinical Research, National Mie Hospital, Tsu, Japan
}

Received June 15, 2013; accepted November 19, 2013; released online March 1, 2014

Copyright (C) 2014 Shuji Hashimoto et al. This is an open access article distributed under the terms of Creative Commons Attribution License, which permits unrestricted use, distribution, and reproduction in any medium, provided the original author and source are credited.

\begin{abstract}
Background: The sentinel surveillance system in Japan provides estimates of nationwide influenza incidence. Although prefectural influenza incidences can be estimated using data from the current surveillance system, such estimates may be imprecise.

Methods: We calculated the numbers of sentinel medical institutions (SMIs) needed in the surveillance system to estimate influenza incidences in prefectures, under the assumption that the standard error rates in $75 \%$ of influenza epidemic cases are less than 10\%. Epidemic cases observed in 47 prefectures during the 2007/2008, 2008/2009, and 2009/2010 seasons, respectively, were used.

Results: The present total number of SMIs was 6669. With respect to current standards, the increases required in prefectures ranged from 0 to 59, and the total increase required in the number of SMIs was 1668.

Conclusions: We used sentinel surveillance data for Japan to calculate the number of SMIs required to estimate influenza incidence in each prefecture.
\end{abstract}

Key words: surveillance; infectious disease; influenza; epidemiology

\section{INTRODUCTION}

Many countries have created systems for sentinel surveillance of infectious diseases. ${ }^{1-5}$ Such systems provide information that is essential for minimizing the burden and impact of an influenza outbreak, but incidence is not obtained directly using data from sentinels. ${ }^{4,6}$ In Japan, sentinel surveillance of influenza is done as part of the National Epidemiological Surveillance of Infectious Diseases (NESID). ${ }^{7}$ Research has determined the number of sentinel medical institutions (SMIs) required to estimate nationwide influenza incidences using sentinel surveillance data. ${ }^{8}$ Moreover, NESID guidelines specify the method for selecting SMIs. ${ }^{9}$ Prefectural governments select SMIs (about 3000 in pediatrics and about 2000 in internal medicine) according to the guidelines. Nationwide influenza incidence is estimated using data from SMIs. ${ }^{10-12}$

Countermeasures against influenza epidemics are planned and implemented locally and nationwide. ${ }^{13}$ Incidence estimates for local areas would be useful if their accuracy was above a certain threshold. Our goal was to use data from sentinel surveillance to obtain accurate estimates of influenza incidence in each prefecture of Japan. Although influenza incidence can be estimated in each prefecture on the basis of the current surveillance system, such estimates may be imprecise. ${ }^{6}$ In previous studies of Japan, the precision of nationwide influenza incidence estimates was examined and discussed, but there have been no such studies at the prefecture level. ${ }^{6,8,10,11}$

In the present study, we used sentinel surveillance data from Japan to determine the number of SMIs required for estimating influenza incidence in each prefecture.

\section{METHODS}

\section{Influenza surveillance in Japan}

The NESID in Japan has been described elsewhere. ${ }^{5-7}$ It is organized by the Ministry of Health, Labour and Welfare (MHLW) and encompasses the sentinel surveillance system 
for influenza. Prefectural governments select SMIs for the influenza surveillance system, and each SMI reports the weekly numbers of influenza cases to the area health center. Health centers notify prefectural governments and the MHLW by using an online computer network.

\section{Surveillance data and method for estimating incidence}

After obtaining permission from the National Institute of Infectious Diseases of Japan, we used SMI reports of influenza data at the NESID for 3 seasons: 2007/2008 (from week 36 of 2007 to week 35 of 2008), 2008/2009 (from week 36 of 2008 to week 27 of 2009), and 2009/2010 (from week 28 of 2009 to week 12 of 2010). There were epidemics of A(H1N1)pdm09 in the 2009/2010 season. ${ }^{14}$ The numbers of medical institutions were obtained from the National Survey of Medical Care Institutions conducted by the MHLW in 2008. ${ }^{15}$

The method for estimating influenza incidence used in the NESID surveillance system was previously described. ${ }^{6,11}$ Influenza incidence in each prefecture, by type of medical institution, was estimated as the total number of influenza patients in SMIs divided by the proportion of SMIs to all medical institutions. Incidence in each prefecture was estimated as the total of influenza incidence estimates for all types of medical institution. Medical institutions were divided into 4 types, as follows: (1) hospital pediatrics departments, (2) pediatrics clinics, (3) internal medicine clinics with a secondary pediatrics practice, and (4) hospital departments of internal medicine and internal medicine clinics with no pediatric practice. These are classified as the first, second, third, and fourth types of medical institution, respectively. The Appendix shows the method of estimating incidence in detail.

\section{Method of determining the standard number of SMIs}

The Japan influenza surveillance system includes 2 types of SMIs. ${ }^{7,9}$ The first comprises hospital pediatrics departments and pediatrics clinics (pediatrics SMI), ie, the first and second types of medical institution. The second comprises internal medicine clinics with a secondary pediatrics practice, hospital departments of internal medicine, and internal medicine clinics with no pediatrics practice (internal medicine SMI), ie, the third and fourth types of medical institution. We calculated the standard number of pediatrics and internal medicine SMIs in prefectures according to the method specified in the NESID guideline. As shown in Table 1, the standard numbers of pediatrics and internal medicine SMIs in areas covered by health centers in prefectures were determined in relation to population size. ${ }^{7,9}$ We divided the standard numbers of pediatrics SMIs into the first and second types of medical institution, proportional to the numbers of all medical institutions. Also, the standard numbers of internal medicine SMIs were divided into the third and fourth types of medical institution.
Table 1. Standard numbers of SMls in areas covered by health centers, by population size

\begin{tabular}{|c|c|c|}
\hline & \multicolumn{2}{|c|}{ Area covered by health center } \\
\hline & Population size & Standard number of SMls \\
\hline \multirow[t]{3}{*}{ Pediatrics SMls } & $<30000$ & 1 \\
\hline & $30000-74999$ & 2 \\
\hline & $\geq 75000$ & $3+(\pi-75000) / 50000$ \\
\hline \multirow[t]{3}{*}{ Internal medicine SMIs } & $<75000$ & 1 \\
\hline & $75000-124999$ & 2 \\
\hline & $\geq 125000$ & $3+(\pi-125000) / 100000$ \\
\hline
\end{tabular}

SMI: sentinel medical institution.

$\pi$ is population size.

\section{Method for determining the number of SMIs needed for estimating prefectural influenza incidence}

As a condition for precise estimation of incidences in prefectures, we assumed that standard error rates for critical proportions of influenza epidemic cases were less than $10 \%$. The standard error rate is defined as the standard error divided by the incidence estimate and was used as an index of the precision of incidence estimates in a previous report that calculated the numbers of SMIs needed for estimating nationwide influenza incidence. ${ }^{8}$ The critical proportions of influenza epidemic cases were given as $25 \%, 50 \%, 75 \%$, and $90 \%$. We assume a critical proportion of $75 \%$ in our proposal. Influenza epidemic cases were represented as means and standard deviations (SDs) of the numbers of influenza patients at all medical institutions, which were obtained using data from SMI reports in 47 prefectures for the 2007/2008, 2008/ 2009 , and 2009/2010 seasons. Out of 141 epidemic cases (47 prefectures multiplied by 3 seasons), 25 were excluded because there were fewer than 3 SMIs of any type of medical institution in a prefecture. Ultimately, 116 epidemic cases were obtained.

To determine the number of SMIs needed for estimating incidence in each prefecture, we first calculated the minimum number of SMIs needed to satisfy the condition that the standard error rate of incidence estimated in the prefecture for an influenza epidemic case was less than 10\% (as described below). Second, using those numbers of SMIs calculated for the 116 influenza epidemic cases, we calculated the number of SMIs required for estimating incidence in the prefecture, thereby satisfying the assumption that the standard error rate of incidence estimates for critical proportions $(25 \%, 50 \%$, $75 \%$, or $90 \%$ ) of influenza epidemic cases was less than $10 \%$.

The method for calculating the minimum required number of SMIs in a prefecture to satisfy the condition that the standard error rate of an incidence estimate for an influenza epidemic case is less than $10 \%$ was as follows. ${ }^{8}$ The suffix of $k$ from 1 to 4 indicates the first, second, third, and fourth types of medical institution, respectively. Consider an influenza epidemic case. For a type of medical institution, such as $k$, the mean and SD of the numbers of influenza patients in all 
medical institutions in the epidemic case are given as $\mu_{k}$ and $\sigma_{k}$, respectively. Let $n_{k}$ and $N_{k}$ be the number of all medical institutions and SMIs, respectively. The values of $\mu_{k}$ and $\sigma_{k}$ were obtained: $n_{k}$ is known and $N_{k}$ is unknown. Note that the incidence is $\alpha_{k}=n_{k} \mu_{k}$. The variance of an incidence estimate is given as $\beta_{k}^{2}=\left\{\left(N_{k}-1\right) n_{k}{ }^{3} /\left(N_{k}\left(n_{k}-1\right)\right)\right\} \sigma_{k}{ }^{2}\left(1 / N_{k}-1 / n_{k}\right){ }^{6,11}$ The standard error rate of the total incidence estimate is expressed as $\sqrt{\beta_{1}^{2}+\beta_{2}^{2}+\beta_{3}^{2}+\beta_{4}^{2}} /\left(\alpha_{1}+\alpha_{2}+\alpha_{3}+\alpha_{4}\right)$. We assumed that $N_{1}$ and $N_{2}$ were equal to the standard numbers of their SMIs (obtained by the method described in Table 1), that $N_{3}$ and $N_{4}$ were not less than the standard numbers of SMIs, and that the ratio of $N_{3}$ to $N_{4}$ was equal to the ratio of the numbers of all medical institutions. These assumptions are discussed below. Thus, from the equation that the standard error rate of the total incidence estimate was equal to $10 \%, N_{3}$ and $N_{4}$ could be obtained by giving $N_{1}, N_{2}$ and the ratio of $N_{3} / N_{4}$. The total number of SMIs in all types of medical institution was estimated as $N_{1}+N_{2}+$ $N_{3}+N_{4}$.

\section{RESULTS}

Table 2 shows the distributions of the numbers of influenza patients in SMIs among the 116 epidemic cases. In hospital pediatrics departments, the mean, $\mathrm{SD}$, and coefficient of variation of the numbers of influenza patients in SMIs ranged widely among the epidemic cases. Median, 25th, and 75th percentiles of the mean numbers of influenza patients in SMIs

Table 2. Distributions of numbers of influenza patients in SMls among 116 epidemic cases

\begin{tabular}{|c|c|c|c|c|}
\hline \multirow{2}{*}{$\begin{array}{c}\text { Number of } \\
\text { influenza patients } \\
\text { in SMls }\end{array}$} & \multicolumn{4}{|c|}{ Type of medical institution ${ }^{a}$} \\
\hline & Type 1 & Type 2 & Type 3 & Type 4 \\
\hline \multicolumn{5}{|l|}{ Means } \\
\hline Minimum ${ }^{b}$ & 66.0 & 97.7 & 49.6 & 26.8 \\
\hline 25th percentile & 159.1 & 242.3 & 112.6 & 96.2 \\
\hline Median & 262.0 & 370.8 & 197.5 & 147.9 \\
\hline 75th percentile & 402.3 & 503.7 & 275.1 & 204.2 \\
\hline Maximum & 1553.1 & 927.3 & 426.2 & 794.1 \\
\hline \multicolumn{5}{|l|}{ Standard deviations } \\
\hline Minimumb & 30.5 & 69.0 & 22.7 & 24.5 \\
\hline 25th percentile & 126.7 & 144.8 & 83.4 & 81.0 \\
\hline Median & 192.0 & 234.3 & 159.3 & 141.8 \\
\hline 75th percentile & 319.3 & 314.0 & 238.0 & 213.7 \\
\hline Maximum & 1631.7 & 887.2 & 667.8 & 719.2 \\
\hline \multicolumn{5}{|c|}{ Coefficients of variation (\%) } \\
\hline Minimum $^{b}$ & 23.3 & 29.8 & 21.1 & 57.1 \\
\hline 25th percentile & 66.4 & 55.2 & 66.6 & 78.8 \\
\hline Median & 78.5 & 65.3 & 87.9 & 94.8 \\
\hline 75th percentile & 90.8 & 73.2 & 105.5 & 113.8 \\
\hline Maximum & 191.2 & 133.1 & 184.9 & 223.5 \\
\hline
\end{tabular}

SMI: sentinel medical institution.

anstitution types are defined in the Methods.

bMinimum, maximum, median, 25th, and 75th percentiles for the 116 epidemic cases. among the 116 epidemic cases were 262, 159, and 402, respectively. Median, 25th, and 75th percentiles of the SDs were 192, 127, and 319. Median, 25th, and 75th percentiles of the coefficients of variation were $79 \%, 66 \%$, and $91 \%$. In other types of medical institutions, the mean, SD, and coefficient of variation of the numbers of influenza patients in SMIs ranged widely among epidemic cases.

As mentioned above, we assumed that the numbers of SMIs needed for estimating influenza incidence in prefectures were equal to their standard numbers of SMIs in hospital pediatrics departments and pediatrics clinics. Table 3 shows the numbers of all medical institutions and the standard numbers of SMIs in prefectures. In hospital pediatrics departments, the standard numbers of SMIs in prefectures ranged from 5 to 65 , and the total was 968 (38.7\% of all medical institutions). In pediatrics clinics, the standard numbers of SMIs in prefectures ranged from 11 to 221, and the total was $2140(38.2 \%)$.

We calculated the numbers of SMIs needed for estimating influenza incidence in prefectures, assuming that the standard error rate of incidence estimates for critical proportions $(25 \%$, $50 \%, 75 \%$, or $90 \%$ ) of influenza epidemic cases was less than $10 \%$. The numbers of SMIs are described as "the numbers of SMIs calculated for critical proportions $(25 \%, 50 \%, 75 \%$, or $90 \%$ ) of epidemic cases". Table 4 shows the numbers of all medical institutions, the standard numbers of SMIs, and the numbers of SMIs needed for estimating prefectural influenza incidence in internal medicine clinics with a secondary pediatrics practice. The standard numbers of prefectural SMIs ranged from 3 to 41 , and the total was 490 (3.3\% of all medical institutions). The numbers of prefectural SMIs for a critical proportion of $25 \%$ of epidemic cases ranged from 5 to 43 , and the values in 32 prefectures were greater than the standard numbers of SMIs. The numbers of prefectural SMIs for a critical proportion of $75 \%$ of epidemic cases ranged from 9 to 43 and were equal to the standard numbers of SMIs in 9 prefectures, namely, Hokkaido, Saitama, Chiba, Tokyo, Kanagawa, Aichi, Osaka, Hyogo, and Fukuoka. The total numbers of SMIs needed for critical proportions of $25 \%, 50 \%$, $75 \%$, and $90 \%$ of epidemic cases were $629(4.3 \%), 770$ (5.2\%), $910(6.2 \%)$, and 1155 (7.8\%), respectively.

Table 5 shows the numbers of all medical institutions, the standard numbers of SMIs, and the numbers of SMIs needed for estimating prefectural influenza incidence in hospital departments of internal medicine and internal medicine clinics with no pediatrics practice. The standard numbers of SMIs in prefectures ranged from 8 to 120, and the total was 1403 (3.3\% of all medical institutions). The numbers of SMIs needed for a critical proportion of $25 \%$ of epidemic cases in prefectures ranged from 21 to 120 , and the values in 32 prefectures were greater than the standard numbers of SMIs. The numbers of SMIs needed for a critical proportion of $75 \%$ of epidemic cases in prefectures ranged from 38 to 120 and were equal to the standard numbers of SMIs in 9 prefectures. 
Table 3. Numbers of all medical institutions and standard numbers of SMls in hospital pediatrics departments and pediatrics clinics

\begin{tabular}{|c|c|c|c|c|}
\hline \multirow[b]{2}{*}{ Prefecture } & \multicolumn{2}{|c|}{ Hospital pediatrics departments } & \multicolumn{2}{|c|}{ Pediatrics clinics } \\
\hline & $\begin{array}{l}\text { No. of all medical } \\
\text { institutions }\end{array}$ & $\begin{array}{l}\text { Standard no. } \\
\text { of SMls }\end{array}$ & $\begin{array}{l}\text { No. of all medical } \\
\text { institutions }\end{array}$ & $\begin{array}{l}\text { Standard no. } \\
\text { of SMls }\end{array}$ \\
\hline Hokkaido & 146 & $58(39.7)$ & 213 & 85 (39.9) \\
\hline Aomori & 33 & $14(42.4)$ & 50 & $21(42.0)$ \\
\hline Iwate & 41 & $17(41.5)$ & 50 & $21(42.0)$ \\
\hline Miyagi & 42 & $18(42.9)$ & 96 & $42(43.8)$ \\
\hline Akita & 26 & $12(46.2)$ & 45 & $21(46.7)$ \\
\hline Yamagata & 24 & $9(37.5)$ & 57 & $20(35.1)$ \\
\hline Fukushima & 43 & $16(37.2)$ & 95 & $34(35.8)$ \\
\hline Ibaraki & 76 & $35(46.1)$ & 83 & $38(45.8)$ \\
\hline Tochigi & 34 & $15(44.1)$ & 73 & $32(43.8)$ \\
\hline Gunma & 36 & $12(33.3)$ & 114 & $40(35.1)$ \\
\hline Saitama & 110 & $45(40.9)$ & 271 & $111(41.0)$ \\
\hline Chiba & 96 & $41(42.7)$ & 226 & $95(42.0)$ \\
\hline Tokyo & 175 & $59(33.7)$ & 649 & $221(34.1)$ \\
\hline Kanagawa & 106 & $42(39.6)$ & 420 & $168(40.0)$ \\
\hline Niigata & 55 & $21(38.2)$ & 102 & $40(39.2)$ \\
\hline Toyama & 33 & $10(30.3)$ & 57 & $17(29.8)$ \\
\hline Ishikawa & 38 & $12(31.6)$ & 56 & $17(30.4)$ \\
\hline Fukui & 29 & $10(34.5)$ & 37 & $12(32.4)$ \\
\hline Yamanashi & 23 & $10(43.5)$ & 29 & $13(44.8)$ \\
\hline Nagano & 63 & $26(41.3)$ & 75 & $30(40.0)$ \\
\hline Gifu & 47 & $16(34.0)$ & 102 & $34(33.3)$ \\
\hline Shizuoka & 51 & $21(41.2)$ & 160 & $64(40.0)$ \\
\hline Aichi & 116 & $44(37.9)$ & 342 & $130(38.0)$ \\
\hline Mie & 40 & $17(42.5)$ & 72 & $30(41.7)$ \\
\hline Shiga & 31 & $12(38.7)$ & 60 & $22(36.7)$ \\
\hline Kyoto & 64 & $25(39.1)$ & 118 & $47(39.8)$ \\
\hline Osaka & 138 & $65(47.1)$ & 326 & $153(46.9)$ \\
\hline Hyogo & 92 & $32(34.8)$ & 286 & 99 (34.6) \\
\hline Nara & 27 & $11(40.7)$ & 56 & $23(41.1)$ \\
\hline Wakayama & 25 & $9(36.0)$ & 58 & $20(34.5)$ \\
\hline Tottori & 16 & $5(31.3)$ & 35 & $11(31.4)$ \\
\hline Shimane & 25 & $8(32.0)$ & 38 & $12(31.6)$ \\
\hline Okayama & 51 & 19 (37.3) & 71 & $27(38.0)$ \\
\hline Hiroshima & 58 & $22(37.9)$ & 135 & $50(37.0)$ \\
\hline Yamaguchi & 37 & $13(35.1)$ & 71 & $26(36.6)$ \\
\hline Tokushima & 35 & $11(31.4)$ & 37 & $11(29.7)$ \\
\hline Kagawa & 28 & $11(39.3)$ & 38 & $15(39.5)$ \\
\hline Ehime & 28 & $10(35.7)$ & 78 & $27(34.6)$ \\
\hline Kouchi & 32 & $12(37.5)$ & 29 & $10(34.5)$ \\
\hline Fukuoka & 83 & 29 (34.9) & 265 & $91(34.3)$ \\
\hline Saga & 25 & $8(32.0)$ & 42 & $14(33.3)$ \\
\hline Nagasaki & 39 & 13 (33.3) & 84 & $27(32.1)$ \\
\hline Kumamoto & 50 & $18(36.0)$ & 82 & $29(35.4)$ \\
\hline Oita & 33 & $12(36.4)$ & 50 & $18(36.0)$ \\
\hline Miyazaki & 26 & $11(42.3)$ & 49 & 21 (42.9) \\
\hline Kagoshima & 40 & $20(50.0)$ & 61 & $30(49.2)$ \\
\hline Okinawa & 36 & $12(33.3)$ & 65 & $21(32.3)$ \\
\hline Totals & 2502 & $968(38.7)$ & 5608 & $2140(38.2)$ \\
\hline
\end{tabular}

SMI: sentinel medical institution.

Percentages of all medical institutions are in parentheses.

The total numbers of SMIs needed for critical proportions of $25 \%, 50 \%, 75 \%$, and $90 \%$ of epidemic cases were 1811 (4.2\%), $2234(5.2 \%), 2651$ (6.2\%), and 3387 (7.9\%), respectively.
The total number of SMIs among all types of medical institutions was 5001. The total numbers of SMIs needed for critical proportions of $25 \%, 50 \%, 75 \%$, and $90 \%$ of epidemic cases, for all types of medical institutions, were 5548, 6112, 
Table 4. Numbers of all medical institutions, standard numbers of SMls, and numbers of SMls needed for estimating prefectural influenza incidence: internal medicine clinics with a secondary pediatric practice

\begin{tabular}{|c|c|c|c|c|c|c|}
\hline \multirow{3}{*}{ Prefecture } & \multirow{3}{*}{$\begin{array}{l}\text { No. of } \\
\text { all medical } \\
\text { institutions }\end{array}$} & \multirow{3}{*}{$\begin{array}{l}\text { Standard no. } \\
\text { of SMls }\end{array}$} & \multicolumn{4}{|c|}{ No. of SMls needed for estimating influenza incidence in prefectures ${ }^{a}$} \\
\hline & & & \multicolumn{4}{|c|}{ Critical proportion of influenza epidemic cases } \\
\hline & & & $25 \%$ & $50 \%$ & $75 \%$ & $90 \%$ \\
\hline Hokkaido & 428 & $17(4.0)$ & $17(4.0)$ & $17(4.0)$ & $17(4.0)$ & $17(4.0)$ \\
\hline Aomori & 183 & $7(3.8)$ & $12(6.6)$ & $17(9.3)$ & $21(11.5)$ & $29(15.8)$ \\
\hline Iwate & 81 & $3(3.7)$ & $5(6.2)$ & 7 (8.6) & $9(11.1)$ & $13(16.0)$ \\
\hline Miyagi & 229 & $9(3.9)$ & $9(3.9)$ & $13(5.7)$ & $16(7.0)$ & $22(9.6)$ \\
\hline Akita & 94 & $4(4.3)$ & $7(7.4)$ & $9(9.6)$ & $12(12.8)$ & $16(17.0)$ \\
\hline Yamagata & 106 & $3(2.8)$ & $7(6.6)$ & $10(9.4)$ & $13(12.3)$ & $17(16.0)$ \\
\hline Fukushima & 297 & $9(3.0)$ & $11(3.7)$ & $17(5.7)$ & $20(6.7)$ & $29(9.8)$ \\
\hline Ibaraki & 348 & $13(3.7)$ & $13(3.7)$ & $16(4.6)$ & $21(6.0)$ & $30(8.6)$ \\
\hline Tochigi & 269 & $9(3.3)$ & $13(4.8)$ & $18(6.7)$ & $22(8.2)$ & $31(11.5)$ \\
\hline Gunma & 295 & $9(3.1)$ & $11(3.7)$ & $16(5.4)$ & $19(6.4)$ & $27(9.2)$ \\
\hline Saitama & 746 & $29(3.9)$ & $29(3.9)$ & $29(3.9)$ & $29(3.9)$ & $29(3.9)$ \\
\hline Chiba & 607 & $24(4.0)$ & $24(4.0)$ & $24(4.0)$ & $24(4.0)$ & $27(4.4)$ \\
\hline Tokyo & 1718 & $41(2.4)$ & $41(2.4)$ & $41(2.4)$ & $41(2.4)$ & $41(2.4)$ \\
\hline Kanagawa & 731 & $31(4.2)$ & $31(4.2)$ & $31(4.2)$ & $31(4.2)$ & $31(4.2)$ \\
\hline Niigata & 227 & $8(3.5)$ & $8(3.5)$ & $12(5.3)$ & $15(6.6)$ & $20(8.8)$ \\
\hline Toyama & 105 & $3(2.9)$ & $7(6.7)$ & $10(9.5)$ & $13(12.4)$ & 17 (16.2) \\
\hline Ishikawa & 88 & $3(3.4)$ & $6(6.8)$ & $8(9.1)$ & $11(12.5)$ & 14 (15.9) \\
\hline Fukui & 124 & $4(3.2)$ & $12(9.7)$ & 17 (13.7) & $21(16.9)$ & $29(23.4)$ \\
\hline Yamanashi & 137 & $5(3.6)$ & $14(10.2)$ & 19 (13.9) & $23(16.8)$ & $31(22.6)$ \\
\hline Nagano & 323 & $11(3.4)$ & $13(4.0)$ & $18(5.6)$ & $22(6.8)$ & $32(9.9)$ \\
\hline Gifu & 436 & $14(3.2)$ & $18(4.1)$ & $24(5.5)$ & $32(7.3)$ & $40(9.2)$ \\
\hline Shizuoka & 323 & $11(3.4)$ & $11(3.4)$ & $12(3.7)$ & $16(5.0)$ & $21(6.5)$ \\
\hline Aichi & 1110 & 43 (3.9) & 43 (3.9) & $43(3.9)$ & 43 (3.9) & 43 (3.9) \\
\hline Mie & 242 & 7 (2.9) & $10(4.1)$ & $15(6.2)$ & 19 (7.9) & $26(10.7)$ \\
\hline Shiga & 206 & $7(3.4)$ & $13(6.3)$ & 17 (8.3) & $22(10.7)$ & $30(14.6)$ \\
\hline Kyoto & 356 & $12(3.4)$ & $12(3.4)$ & $14(3.9)$ & $19(5.3)$ & $25(7.0)$ \\
\hline Osaka & 970 & 31 (3.2) & 31 (3.2) & $31(3.2)$ & $31(3.2)$ & 31 (3.2) \\
\hline Hyogo & 571 & $18(3.2)$ & $18(3.2)$ & $18(3.2)$ & $18(3.2)$ & $21(3.7)$ \\
\hline Nara & 186 & $6(3.2)$ & $12(6.5)$ & $17(9.1)$ & $20(10.8)$ & $28(15.1)$ \\
\hline Wakayama & 163 & $4(2.5)$ & $9(5.5)$ & $13(8.0)$ & $17(10.4)$ & $22(13.5)$ \\
\hline Tottori & 102 & $3(2.9)$ & $11(10.8)$ & $16(15.7)$ & $20(19.6)$ & $26(25.5)$ \\
\hline Shimane & 155 & $4(2.6)$ & $13(8.4)$ & $18(11.6)$ & $22(14.2)$ & $30(19.4)$ \\
\hline Okayama & 353 & $9(2.5)$ & $14(4.0)$ & $20(5.7)^{\prime}$ & $25(7.1)$ & $35(9.9)$ \\
\hline Hiroshima & 296 & $9(3.0)$ & $9(3.0)$ & $11(3.7)$ & $14(4.7)$ & $19(6.4)$ \\
\hline Yamaguchi & 136 & $4(2.9)$ & $7(5.1)$ & $9(6.6)$ & $12(8.8)$ & $16(11.8)$ \\
\hline Tokushima & 184 & $4(2.2)$ & $14(7.6)$ & $19(10.3)$ & $23(12.5)$ & $32(17.4)$ \\
\hline Kagawa & 88 & $3(3.4)$ & $7(8.0)$ & $10(11.4)$ & $13(14.8)$ & 17 (19.3) \\
\hline Ehime & 110 & $4(3.6)$ & $6(5.5)$ & $8(7.3)$ & $10(9.1)$ & $14(12.7)$ \\
\hline Kouchi & 68 & $3(4.4)$ & $6(8.8)$ & $8(11.8)$ & $11(16.2)$ & $14(20.6)$ \\
\hline Fukuoka & 477 & $15(3.1)$ & $15(3.1)$ & $15(3.1)$ & $15(3.1)$ & $19(4.0)$ \\
\hline Saga & 124 & $4(3.2)$ & $10(8.1)$ & $14(11.3)$ & $17(13.7)$ & $24(19.4)$ \\
\hline Nagasaki & 166 & $5(3.0)$ & $8(4.8)$ & $11(6.6)$ & $14(8.4)$ & 19 (11.4) \\
\hline Kumamoto & 241 & $8(3.3)$ & $9(3.7)$ & $14(5.8)$ & $18(7.5)$ & $23(9.5)$ \\
\hline Oita & 124 & $4(3.2)$ & $8(6.5)$ & $10(8.1)$ & $14(11.3)$ & $18(14.5)$ \\
\hline Miyazaki & 92 & $3(3.3)$ & $6(6.5)$ & $8(8.7)$ & 11 (12.0) & $14(15.2)$ \\
\hline Kagoshima & 215 & $7(3.3)$ & $9(4.2)$ & $13(6.0)$ & $17(7.9)$ & $23(10.7)$ \\
\hline Okinawa & 140 & $6(4.3)$ & $10(7.1)$ & $13(9.3)$ & $17(12.1)$ & $23(16.4)$ \\
\hline Totals & 14770 & $490(3.3)$ & $629(4.3)$ & $770(5.2)$ & $910(6.2)$ & $1155(7.8)$ \\
\hline
\end{tabular}

SMI: sentinel medical institution.

Percentages of all medical institutions are in parentheses.

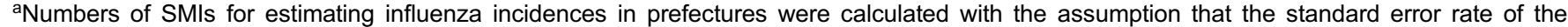
incidence estimate for a given critical proportion $(25 \%, 50 \%, 75 \%$, or $90 \%)$ of influenza epidemic cases was less than $10 \%$. 
Table 5. Numbers of all medical institutions, standard numbers of SMls, and numbers of SMls needed for estimating influenza incidence in prefectures: hospital departments of internal medicine and internal medicine clinics with no pediatric practice

\begin{tabular}{|c|c|c|c|c|c|c|}
\hline \multirow{3}{*}{ Prefecture } & \multirow{3}{*}{$\begin{array}{c}\text { No. of } \\
\text { all medical } \\
\text { institutions }\end{array}$} & \multirow{3}{*}{$\begin{array}{l}\text { Standard no. } \\
\text { of SMls }\end{array}$} & \multicolumn{4}{|c|}{ No. of SMls needed for estimating influenza incidence in prefectures ${ }^{a}$} \\
\hline & & & \multicolumn{4}{|c|}{ Critical proportion of influenza epidemic cases } \\
\hline & & & $25 \%$ & $50 \%$ & $75 \%$ & $90 \%$ \\
\hline Hokkaido & 1652 & $68(4.1)$ & $68(4.1)$ & $68(4.1)$ & $68(4.1)$ & $68(4.1)$ \\
\hline Aomori & 380 & $15(3.9)$ & $26(6.8)$ & $36(9.5)$ & $44(11.6)$ & $61(16.1)$ \\
\hline Iwate & 485 & $21(4.3)$ & $31(6.4)$ & $44(9.1)$ & $55(11.3)$ & $75(15.5)$ \\
\hline Miyagi & 705 & $28(4.0)$ & $28(4.0)$ & $40(5.7)$ & $50(7.1)$ & $68(9.6)$ \\
\hline Akita & 423 & $18(4.3)$ & $30(7.1)$ & $43(10.2)$ & $56(13.2)$ & $72(17.0)$ \\
\hline Yamagata & 472 & $14(3.0)$ & $31(6.6)$ & $43(9.1)$ & $56(11.9)$ & $75(15.9)$ \\
\hline Fukushima & 711 & $21(3.0)$ & $27(3.8)$ & $40(5.6)$ & $49(6.9)$ & $68(9.6)$ \\
\hline Ibaraki & 817 & $31(3.8)$ & $31(3.8)$ & $38(4.7)$ & $48(5.9)$ & $71(8.7)$ \\
\hline Tochigi & 604 & $19(3.1)$ & $28(4.6)$ & $40(6.6)$ & 49 (8.1) & 69 (11.4) \\
\hline Gunma & 699 & $23(3.3)$ & $26(3.7)$ & $38(5.4)$ & $46(6.6)$ & $64(9.2)$ \\
\hline Saitama & 1577 & $60(3.8)$ & $60(3.8)$ & $60(3.8)$ & $60(3.8)$ & $62(3.9)$ \\
\hline Chiba & 1436 & $56(3.9)$ & $56(3.9)$ & $56(3.9)$ & $56(3.9)$ & $64(4.5)$ \\
\hline Tokyo & 5074 & $120(2.4)$ & $120(2.4)$ & $120(2.4)$ & $120(2.4)$ & $120(2.4)$ \\
\hline Kanagawa & 2310 & $99(4.3)$ & $99(4.3)$ & $99(4.3)$ & $99(4.3)$ & $99(4.3)$ \\
\hline Niigata & 803 & $28(3.5)$ & $28(3.5)$ & $41(5.1)$ & $52(6.5)$ & $69(8.6)$ \\
\hline Toyama & 418 & $14(3.3)$ & $29(6.9)$ & $40(9.6)$ & $52(12.4)$ & $70(16.7)$ \\
\hline Ishikawa & 455 & $16(3.5)$ & $29(6.4)$ & $42(9.2)$ & $55(12.1)$ & $74(16.3)$ \\
\hline Fukui & 242 & $9(3.7)$ & $24(9.9)$ & $32(13.2)$ & $40(16.5)$ & $57(23.6)$ \\
\hline Yamanashi & 260 & $10(3.8)$ & $26(10.0)$ & 35 (13.5) & 44 (16.9) & 59 (22.7) \\
\hline Nagano & 654 & $22(3.4)$ & $26(4.0)$ & $36(5.5)$ & $44(6.7)$ & $66(10.1)$ \\
\hline Gifu & 519 & $17(3.3)$ & $21(4.0)$ & $28(5.4)$ & $38(7.3)$ & $47(9.1)$ \\
\hline Shizuoka & 1107 & $37(3.3)$ & $37(3.3)$ & $42(3.8)$ & $53(4.8)$ & $71(6.4)$ \\
\hline Aichi & 1698 & $66(3.9)$ & $66(3.9)$ & $66(3.9)$ & $66(3.9)$ & $66(3.9)$ \\
\hline Mie & 694 & $21(3.0)$ & $30(4.3)$ & $43(6.2)$ & 55 (7.9) & 75 (10.8) \\
\hline Shiga & 422 & $15(3.6)$ & $26(6.2)$ & $36(8.5)$ & $45(10.7)$ & 62 (14.7) \\
\hline Kyoto & 1053 & $36(3.4)$ & $36(3.4)$ & $42(4.0)$ & $55(5.2)$ & $74(7.0)$ \\
\hline Osaka & 3227 & $103(3.2)$ & $103(3.2)$ & $103(3.2)$ & $103(3.2)$ & $103(3.2)$ \\
\hline Hyogo & 1927 & $59(3.1)$ & $59(3.1)$ & $59(3.1)$ & $59(3.1)$ & $72(3.7)$ \\
\hline Nara & 442 & $14(3.2)$ & $28(6.3)$ & $40(9.0)$ & $48(10.9)$ & 66 (14.9) \\
\hline Wakayama & 575 & $14(2.4)$ & $32(5.6)$ & $46(8.0)$ & $60(10.4)$ & 78 (13.6) \\
\hline Tottori & 242 & $8(3.3)$ & 27 (11.2) & 37 (15.3) & $46(19.0)$ & $61(25.2)$ \\
\hline Shimane & 347 & $9(2.6)$ & $29(8.4)$ & 40 (11.5) & $49(14.1)$ & $67(19.3)$ \\
\hline Okayama & 711 & $18(2.5)$ & $29(4.1)$ & $40(5.6)$ & $50(7.0)$ & 71 (10.0) \\
\hline Hiroshima & 1303 & $38(2.9)$ & $38(2.9)$ & $47(3.6)$ & $63(4.8)$ & $82(6.3)$ \\
\hline Yamaguchi & 668 & $20(3.0)$ & $32(4.8)$ & $45(6.7)$ & $59(8.8)$ & 79 (11.8) \\
\hline Tokushima & 396 & $9(2.3)$ & $29(7.3)$ & $40(10.1)$ & $49(12.4)$ & $68(17.2)$ \\
\hline Kagawa & 378 & $13(3.4)$ & $32(8.5)$ & $43(11.4)$ & 55 (14.6) & 73 (19.3) \\
\hline Ehime & 624 & $20(3.2)$ & $31(5.0)$ & $45(7.2)$ & $58(9.3)$ & 80 (12.8) \\
\hline Kouchi & 387 & $11(2.8)$ & $34(8.8)$ & $47(12.1)$ & $60(15.5)$ & $80(20.7)$ \\
\hline Fukuoka & 1854 & $58(3.1)$ & $58(3.1)$ & $58(3.1)$ & $58(3.1)$ & $72(3.9)$ \\
\hline Saga & 365 & $11(3.0)$ & $30(8.2)$ & $41(11.2)$ & $51(14.0)$ & $70(19.2)$ \\
\hline Nagasaki & 629 & $20(3.2)$ & $29(4.6)$ & $41(6.5)$ & $53(8.4)$ & 72 (11.4) \\
\hline Kumamoto & 746 & $23(3.1)$ & $29(3.9)$ & $42(5.6)$ & $54(7.2)$ & $73(9.8)$ \\
\hline Oita & 541 & $15(2.8)$ & $34(6.3)$ & $45(8.3)$ & 59 (10.9) & 79 (14.6) \\
\hline Miyazaki & 525 & $18(3.4)$ & $34(6.5)$ & $48(9.1)$ & $62(11.8)$ & $81(15.4)$ \\
\hline Kagoshima & 779 & $24(3.1)$ & $33(4.2)$ & 48 (6.2) & $61(7.8)$ & $82(10.5)$ \\
\hline Okinawa & 318 & $14(4.4)$ & $22(6.9)$ & $31(9.7)$ & $39(12.3)$ & $52(16.4)$ \\
\hline Totals & 42654 & 1403 (3.3) & $1811(4.2)$ & $2234(5.2)$ & 2651 (6.2) & 3387 (7.9) \\
\hline
\end{tabular}

SMI: sentinel medical institution.

Percentages of all medical institutions are in parentheses.

aNumbers of SMls for estimating influenza incidences in prefectures were calculated with the assumption that the standard error rate of the incidence estimate for a given critical proportion $(25 \%, 50 \%, 75 \%$, or $90 \%)$ of influenza epidemic cases was less than $10 \%$. 


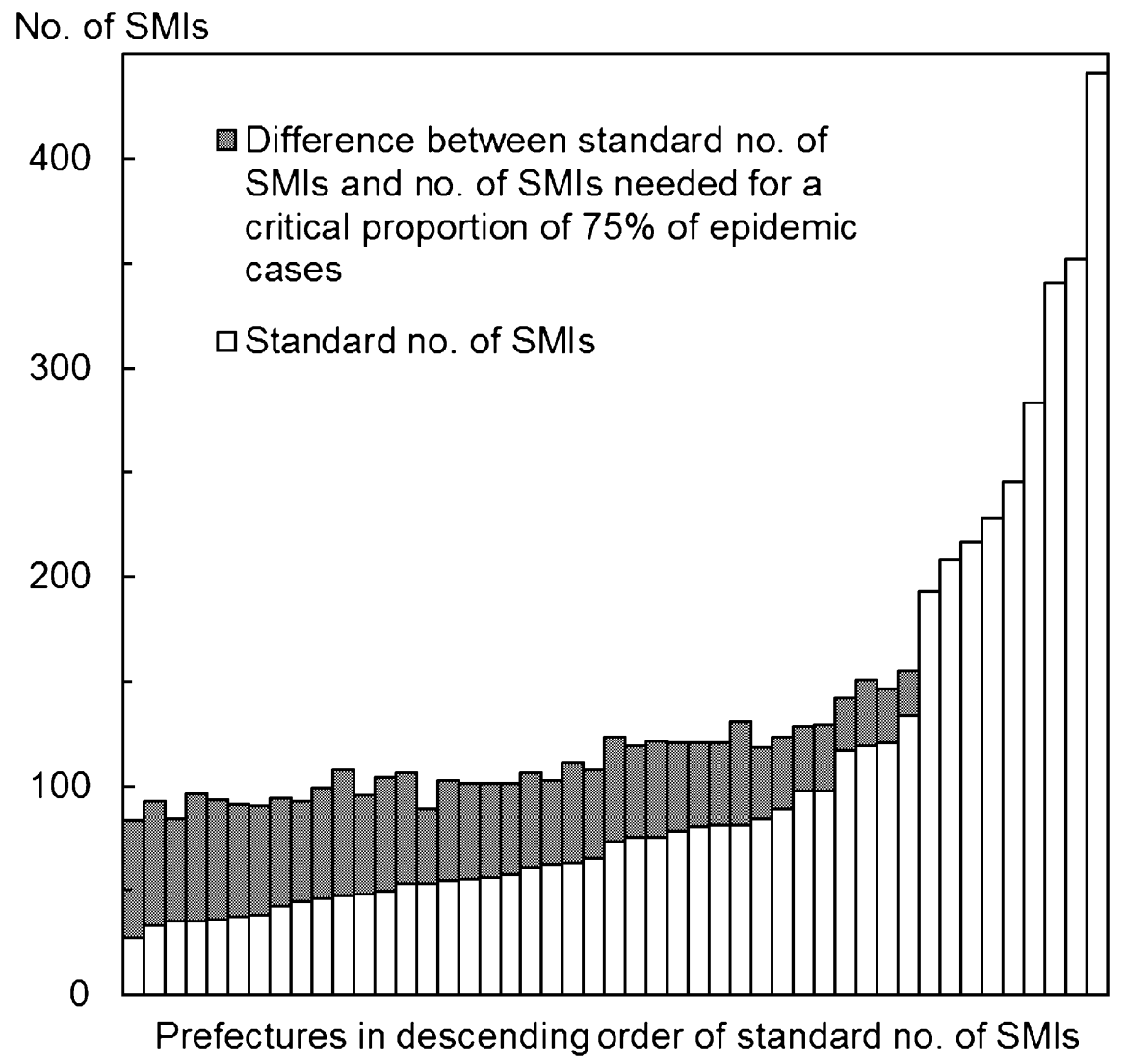

Figure. The standard numbers of SMls and the numbers of SMls needed for estimating prefectural influenza incidence, for all types of medical institutions. SMI: sentinel medical institution.

6669 , and 7650, respectively. The Figure shows the standard numbers of SMIs and the numbers of SMIs needed for estimating prefectural influenza incidence, for all types of medical institutions. The differences between the standard numbers of SMIs and the proposed numbers of SMIs for a critical proportion of $75 \%$ of epidemic cases in prefectures ranged from 0 to 59 , and the total was 1668 .

\section{DISCUSSION}

\section{Influenza surveillance and numbers of SMIs}

The Japanese NESID guidelines specify the method to be used for determining the standard number of SMIs in the influenza surveillance system. ${ }^{7,9}$ The aim of the guidelines is to facilitate detection of epidemics in local areas and incidence estimation nationwide rather than by prefecture. ${ }^{6,16}$ In reality, the numbers of SMIs selected in prefectures were nearly equal to those specified in the standards. ${ }^{17}$ Nationwide annual incidence estimates of influenza have been reported, and their standard error rates were found to be less than $5 \% .^{6,11,12}$

\section{Numbers of SMls and precision of prefectural influenza incidence estimates}

In 32 of the 47 prefectures, the standard number of SMIs in the prefecture was less than the number of SMIs needed for a critical proportion of $25 \%$ of epidemic cases, which means that the standard error rates for influenza incidence estimates in those prefectures would frequently $(>75 \%$ of epidemic cases) exceed $10 \%$ and suggests that, under the current surveillance system, the precision of influenza incidence estimates would be insufficient in many prefectures. We calculated the numbers of SMIs needed for estimating prefectural influenza incidence under the assumption that the standard error rate of the incidence estimate in $75 \%$ of influenza epidemic cases was less than $10 \%$. We propose that prefectural governments increase the number of SMIs to the levels we have specified, as the standard error rates of influenza incidence estimates would then frequently ( $>75 \%$ of epidemic cases) be less than $10 \%$.

\section{Increase of SMls in prefectures and feasibility}

Our proposal would increase the number of internal medicine clinics with a secondary pediatrics practice (third type of medical institution) and hospital departments of internal medicine and internal medicine clinics with no pediatrics practice (fourth type of medical institution). We assumed that the numbers of SMIs needed for estimating influenza incidence in prefectures were equal to the standard numbers of SMIs in the other 2 types of medical institutions, namely, hospital pediatrics departments and pediatric clinics. The increase from the standard numbers of SMIs in prefectures ranged from 0 to 59 for the third and fourth types of medical 
institutions. For these 2 types of medical institutions, the proportion of SMIs to all medical institutions in prefectures that implemented our proposal would be less than 17\% (as shown in Tables 4 and 5), which is less than the proportion of the first and second types of medical institution ( $\geq 30 \%$ of the standard numbers of SMIs shown in Table 3). ${ }^{8,15}$ Thus, an increase in prefectural SMIs in accordance with our proposal is feasible.

\section{Main assumption for determining the number of SMls needed for estimating prefectural influenza incidence}

The standard error rate is commonly used as an index of estimate precision. ${ }^{8,18}$ A primary assumption of the present study is that the standard error rate of the incidence estimate in $75 \%$ of influenza epidemic cases was less than $10 \%$, as that seemed an appropriate level of precision for producing prefectural influenza incidence estimates. ${ }^{19}$ For example, when total incidence is 100000 and the standard error rate of the estimate is $10 \%$, the approximate $95 \%$ confidence interval is 80000 to $120000 .^{6}$ In a previous study of the numbers of SMIs needed to estimate nationwide incidences in Japan, the standard error rate was $5 \%$ for sentinel surveillances of influenza and pediatric diseases and 10\% for sentinel surveillances of ophthalmologic and sexually transmitted diseases. ${ }^{8}$ A standard error rate of $5 \%$ has frequently been used for determining the sample size of surveys in health statistics. ${ }^{18}$ A previous study used a standard error rate of $10 \%$ in consideration of the minimum required level of precision for incidence estimates and the feasibility of selecting SMIs in prefectures. ${ }^{8}$ In the present study, the total number of SMIs required for estimating prefectural incidence, assuming a standard error rate of $10 \%$, was 6669 , and the total increase from the standard number of SMIs was 1668 . In contrast, if we used a 5\% standard error rate for influenza incidence estimates in each prefecture, the total number of SMIs required would be greater than 10000 , which is not feasible.

Under the primary assumption described above, the critical proportion of influenza epidemic cases was 75\%. We considered $75 \%$ of epidemic cases as the proportion needed to maintain the precision of incidence estimates above a desirable threshold. There were no definite reasons for using a critical proportion of $75 \%$. The numbers of SMIs needed for $50 \%$ and $90 \%$ of influenza epidemic cases are therefore presented in Tables 4 and 5, respectively. If the critical proportion of epidemic cases was higher or lower than $75 \%$ (eg, $50 \%$ or $90 \%$ ), the numbers of SMIs needed increased or decreased. The influenza epidemic cases observed in 47 prefectures in 3 seasons were used and are more appropriate than hypothetical cases. ${ }^{8}$ Although the epidemic cases included epidemics of $\mathrm{A}(\mathrm{H} 1 \mathrm{~N} 1) \mathrm{pdm} 09,{ }^{14}$ the median, 25th, and 75 th percentiles of means and SDs of the numbers of influenza patients in SMIs among epidemic cases, not including the 2009/2010 season, did not change greatly.

\section{Other assumptions in determining the number of SMls needed for estimating prefectural influenza incidence}

We made another assumption, ie, that the numbers of SMIs needed for estimating prefectural influenza incidences were equal to the standard numbers of SMIs in hospital pediatrics departments and pediatrics clinics. One reason for this assumption is that the standard numbers of SMIs were sufficiently large. Without this assumption, the numbers of SMIs in these 2 types of medical institutions would be at or below the standard numbers of SMIs for almost all prefectures. Another reason was that proposing SMI numbers that were less than the standards would not be reasonable. The standards were determined by considering the several roles of SMIs in these 2 types of medical institutions, such as detection of epidemics of pediatric infectious diseases in local areas. $6,7,20$

We divided the standard numbers of pediatrics SMIs into 2 types of medical institutions (hospital pediatrics departments and pediatrics clinics), proportional to the numbers of all medical institutions. We did this to adhere to NESID guidelines, which specify that SMIs should be selected as randomly and as representatively as possible from among all medical institutions in an area. ${ }^{7,9}$ For the same reason, we assumed that the ratio of SMIs in the other 2 types of medical institutions (internal medicine clinics with a secondary pediatrics practice and hospital internal medicine departments/internal medicine clinics with no pediatrics practice) was equal to the ratio among all medical institutions.

\section{Problems and limitations}

We attempted to obtain accurate estimates of influenza incidence in each prefecture, using influenza sentinel surveillance data from Japan. A critical problem in achieving this goal is accurately diagnosing influenza. Surveillance guidelines specify the case definition of influenza. ${ }^{7,8}$ When estimating influenza incidence, a key assumption is that SMIs are randomly selected from all medical institutions. ${ }^{6,11}$ However, SMI recruitment is to some extent voluntary. ${ }^{6,17}$ We believe that it is not sufficient to evaluate bias in incidence estimates caused by violation of this assumption. ${ }^{6,11}$ Surveys of all influenza patients at all medical institutions in selected areas would provide useful information. Additional detailed studies are therefore warranted.

\section{Conclusion}

We calculated the numbers of SMIs needed to estimate prefectural influenza incidences in the NESID in Japan, assuming a standard error rate of less than $10 \%$ for $75 \%$ of influenza epidemic cases. The total number of SMIs needed was 6669. The increase from the standard number of SMIs required by NESID guidelines ranged from 0 to 59 in prefectures, and the total number needed was 1668. The 
standard error rate of an estimate of influenza incidence would frequently $(>75 \%$ of epidemic cases) be less than $10 \%$ in prefectures with the proposed number of SMIs but would frequently be greater than $10 \%$ in many prefectures that have only the standard number of SMIs.

\section{ONLINE ONLY MATERIALS}

Abstract in Japanese.

\section{ACKNOWLEDGMENTS}

This study was supported by a Grant-in-Aid from the Ministry of Health, Labour and Welfare, Japan for Research on Emerging and Re-emerging Infectious Diseases.

Conflicts of interest: None declared.

\section{APPENDIX}

\section{Method for estimating incidence}

The method for estimating incidence is as follows. ${ }^{6,11}$ Consider the distribution of incidences in medical institutions. Let $m$ be an integer greater than the largest incidence among medical institutions, $n$ be the number of all medical institutions, and $n_{i}$ be the number of medical institutions with an incidence of $i$ for $i=0,1, \ldots, m$. Let $N$ be the number of SMIs and $N_{i}$ be the number of SMIs with an incidence of $i$ for $i=0,1, \ldots, m$. The constants of $n$ and $N$ are known, and those of $\left\{n_{i}\right\}$ are unknown. $\left\{N_{i}\right\}$ are obtained from sentinel surveillance and follow a multi-hypergeometric distribution under the condition that $N$ is fixed under the assumption that SMIs are randomly selected in all medical institutions.

Let $\alpha$ be the total incidence in all medical institutions, and note that $\alpha=\Sigma i^{*} n_{i}$. The estimate of $\alpha$ is expressed as $\alpha^{\wedge}=\Sigma i^{*} N_{i}{ }^{*} n / N$, ie, the incidence is estimated as the total incidence in SMIs $\left(\Sigma i^{*} N_{i}\right)$ divided by the proportion of SMIs among all medical institutions $(\mathrm{N} / n)$.

Consider that incidences in some strata, such as type of medical institution, are estimated using the above method. Let $k$ be the number of strata and $\alpha_{1} \wedge, \alpha_{2} \wedge, \ldots, \alpha_{k} \wedge$ the estimated incidences in the strata. The total incidence is estimated as $\alpha_{t}^{\wedge}=\alpha_{1}^{\wedge}+\alpha_{2}^{\wedge}+\ldots+\alpha_{k}^{\wedge}$.

\section{REFERENCES}

1. Costagliola D, Flahault A, Galinec D, Garnerin P, Menares J, Valleron AJ. A routine tool for detection and assessment of epidemics of influenza-like syndromes in France. Am J Public Health. 1991;81:97-9.

2. Thacker SB, Stroup DF. Future direction for comprehensive public health surveillance and health information systems in the United States. Am J Epidemiol. 1994;140:383-97.

3. Matter HC, Cloetta J, Zimmermann H. Measles, mumps, and rubella: monitoring in Switzerland through a sentinel network, 1986-94. J Epidemiol Community Health. 1995;49 Suppl 1:4-8.

4. Fleming DM, Zambon M, Bartelds AI. Population estimates of persons presenting to general practitioners with influenza-like illness, 1987-96: a study of the demography of influenza-like illness in sentinel practice networks in England and Wales, and in The Netherlands. Epidemiol Infect. 2000;124:245-53.

5. Taniguchi K, Hashimoto S, Kawado M, Murakami Y, Izumida $\mathrm{M}$, Ohta A, et al. Overview of infectious disease surveillance system in Japan, 1999-2005. J Epidemiol. 2007;17 Suppl: S3-13.

6. Hashimoto S, Murakami Y, Taniguchi K, Shindo N, Osaka K, Fuchigami $\mathrm{H}$, et al. Annual incidence rate of infectious diseases estimated from sentinel surveillance data in Japan. J Epidemiol. 2003;13:136-41.

7. Infectious Disease Surveillance Center, National Institute of Infectious Diseases. The National Epidemiological Surveillance of Infectious Diseases in compliance with the enforcement of the new Infectious Diseases Control Law. IASR. 1999;20(4): No. 230.

8. Hashimoto S, Murakami Y, Taniguchi K, Nagai M. Determination of the numbers of monitoring medical institutions for estimating incidence rates in the surveillance of infectious diseases in Japan. Nihon Koshu Eisei Zasshi. 1999;46: 1068-77 (in Japanese).

9. Tuberculosis and Infectious Diseases Control Division, Health Service Bureau, the Ministry of Health, Labour and Welfare of Japan. The guideline for National Epidemiological Surveillance of Infectious Diseases (kansensho-hasseidokochosajigyojissiyoko). Weekly News of Public Health (Shukan-hokeneisei). 1999;998:14-26 (in Japanese).

10. Hashimoto S, Kawado M, Murakami Y, Tada Y, Shigematsu M, Taniguchi K, et al. Incidence of infectious diseases estimated by the surveillance data in 2002-2004 in Japan. Nihon Koshu Eisei Zasshi. 2006;53:794-9 (in Japanese).

11. Kawado M, Hashimoto S, Murakami Y, Izumida M, Ohta A, Tada Y, et al. Annual and weekly incidence rates of influenza and pediatric diseases estimated from infectious disease surveillance data in Japan, 2002-2005. J Epidemiol. 2007;17 Suppl:S32-41.

12. Infectious Disease Surveillance Center, National Institute of Infectious Diseases. 2009/10 influenza season, Japan. IASR. 2010;31:248-50.

13. Nelson KE, Williams CM, Graham NM. Infectious Disease Epidemiology: Theory and Practice. Gaithersburg: Aspen Publishers Inc; 2001.

14. Infectious Disease Surveillance Center, National Institute of Infectious Diseases. Pandemic (H1N1) 2009 in Japan, May-September 2009. IASR. 2009;30:255-6.

15. Statistics and Information Department, Minister's Secretariat, the Ministry of Health, Labour and Welfare of Japan. The National Survey of Medical Care Institutions 2008. Tokyo: Health and Welfare Statistics Association of Japan; 2010 (in Japanese).

16. Hashimoto S, Murakami Y, Taniguchi K, Nagai M. Detection of epidemics in their early stage through infectious disease surveillance. Int J Epidemiol. 2000;29:905-10.

17. Murakami Y, Hashimoto S, Taniguchi K, Kosaka K, Fuchigami $H$, Nagai M. Distribution of monitoring stations in the 
surveillance of infectious disease after the legislation of new infectious diseases control law in Japan. Nihon Koshu Eisei Zasshi. 2003;50:732-8 (in Japanese).

18. Health and Welfare Statistics Association of Japan. Textbook of Health and Welfare Statistics. 5th edition. Tokyo: Health and Welfare Statistics Association of Japan; 2009 (in Japanese).

19. Hashimoto S, Fukutomi K, Shimizu H, Ohno Y, Nagai M,
Yanagawa H. A study on methodological issues in nationwide epidemiological surveys of intractable diseases. Bull Inst Public Health. 1993;42:219-28 (in Japanese).

20. Murakami Y, Hashimoto S, Taniguchi K, Osaka K, Fuchigami $\mathrm{H}$, Nagai M. Evaluation of a method for issuing warnings preepidemics and epidemics in Japan by infectious diseases surveillance. J Epidemiol. 2004;14:33-40. 